\title{
Brazilian Vascular Journal
}

\author{
Brazilian Vascular Journal
}

Winston Bonetti Yoshida', Airton D elduque Frankini

Jornal Vascular Brasileiro (J V asc Bras) experimentou grande desenvolvimento ao longo do tempo e adquiriu credibilidade crescente entre osleitores, como fruto de um trabalho contínuo de aperfeiçoamento em suas sucessivas edições. Como coroamento dessetrabaIho perene de intransigência com a qualidade, o J V asc Bras passou a ser indexado no SciELO a partir de janeiro de 2006. Ainda há muito por fazer para o seu crescimento. Estamos aguardando resposta de solicitação de auxílio financeiro em órgãos oficiais defomento e temos como meta prioritária futura a indexação na MEDLINE. Assim, se essas iniciativas forem bemsucedidas, de um lado teremos tranqüilidade adicional para com os custosfinanceiros da revista e, deoutro, um indexador importantepara atrair novosartigosecontribuições dos autores nacionais e internacionais.

Para divulgar a produção científica do J V asc Bras junto à comunidadecientífica internacional, foi criado, na gestão anterior, paralelamente, o Brazilian Vascular J ournal, que seria a edição em língua inglesa e impressa em papel do J Vasc Bras. Essa revista foi sempre composta pela junção de dois números sucessivos do J V asc Bras, sendo contínua e gratuitamente distribuída para instituições universitárias, bibliotecas e pesquisadores renomados do exterior.
Entretanto, durante o processo de indexação no SciELO , foi levantada a questão de termos, na prática, duas revistas, sendo uma em português e outra em inglês, com o mesmo conteúdo, mas com números de registro diferentes. I sso criaria um impasse em termos de citação de nossos artigos pel os autorese, conseqüentemente, uma dificuldade de se computar o número de citações, queé o principal indicador do fator de impacto de uma publicação científica. 0 fator de impacto mede 0 número de citações de artigos da revista por diferentes autores, proporcionalmente ao número de artigos publicados. Assim, ao termos duas revistas, as citações ficariam diluídas entre ambas.

Essa questão foi levantada pelo presente editor na convenção da Sociedade Brasileira de Angiologia e de Cirurgia V ascular (SBACV), realizada em julho deste ano em São Paulo, e pareceu ser consensual que uma delas deveria ser extinta. Após discussões com editores e diretoria da SBACV, chegamos à conclusão de que 0 Braz V asc J deveria ser excluído. As razões que determinaram essa escolha foram:

- 0 J Vasc Bras já tem edições em inglês, sendo acessível tanto em inglês como em português no SciELO (www.scielo.br) e também na página da revista na internet (www.jvascbr.com.br). 
- As citações dos artigos através de acesso a essas fontes contabilizariam fator de impacto exclusivamente para o J V asc Bras.

- Todo esforço de crescimento da revista ficaria concentrado em umaúnica publicação, a qual continuaria a ser divulgada no exterior, agora por meio de cartas, convidando as instituições, bibliotecas e pesquisadores a observarem o conteúdo de nossa produção nas páginas citadas. Além disso, haveria uma vantagem adicional ao leitor, que estaria com o texto no momento de sua edição enão precisaria aguardar 6 meses para acumular duas edições da revista, como ocorre na versão em papel do Braz Vasc J, desatualizando as referências.

Valeressaltar que, denenhumamaneira, tal decisão foi calcada em aspectos econômicos, pois já há muito tempo a gestão financeira da revista está equilibrada, não representando ônus para a SBACV , mesmo com a publicação em papel da versão em inglês. Foi simplesmente 0 aspecto técnico apontado 0 motivo dessa decisão.

Evidentementeque, mais do queesseaspecto levantado, o progresso da revista dependedosautoressubmeterem seus trabalhos para publicação. N esse sentido, estamos avançando, mas precisamos de muito mais empenho doscolegas para continuar com pontualidade e qualidade editorial, requisitos fundamentais para mantermoso SciELO epara pleitearmoso M ED LIN E. O srevisores da revista também precisam trabalhar com mais agilidade e necessitam publicar seus artigos no J $\checkmark$ asc Bras, demonstrando que acreditam no periódico oficial da SBACV. C om um grande aporte de artigos, a revista pode ser aprimorada continuamente e aprovada no M ED LINE. Essa indexação atrairá maior número de artigos nacionais e internacionais, fazen do um ciclo vicioso positivo, em quemaisartigos publicadosredundarão em mais citações e maior fator de impacto, fechando o ciclo.

D eve-se ressaltar que, mesmo sem ainda ter a indexação M EDLINE, temos recebido alguns artigos de autores estrangeiros, fato este que valoriza nossa revista. C om certeza, aindexação M ED LIN E éa expectativa de todos os colegas da SBACV, mas, para tal, o trabalho de escrever e enviar artigos para o J V asc Bras precisa ser incrementado. N ão falta produção científica em nossa sociedade. $\mathrm{N}$ ecessitamos apenas mudar um hábito cultural em nosso meio de só apresentar essa produção em congressos, restringindo a visibilidade do nosso trabalho. 0 melhor canal de divulgação dessa pesquisa é, na verdade, a nossa revista, pois será vista epossivel mente citada - por um número muito grande de pesquisadores e especialistas do Brasil, América Latina e Espanha, atualmente o foco do SciELO .

Portanto, vamos contribuir para o desenvolvimento e crescimento do J Vasc Bras, enviando artigos e confiando em que as decisões que estão sendo tomadas são decaráter técnico evisam valorizar ainda maiso que, com muito esforço, foi construído.

\section{Colega Associado da SBACV}

Você está convidado a participar do crescimento e consolidação do J Vasc Bras - como autor, leitor ou revisor.

Leia e divulgue; conheça as normas e submeta seus trabalhos.

\section{Jornal Vascular Brasileiro - Secretaria E ditorial}

Av. Protásio Alves, 1981 - sala 401

CEP 90410-002 - Porto Alegre, RS - Fone: (51) 3388.5000

E-mail: jvascbr@terra.com.br

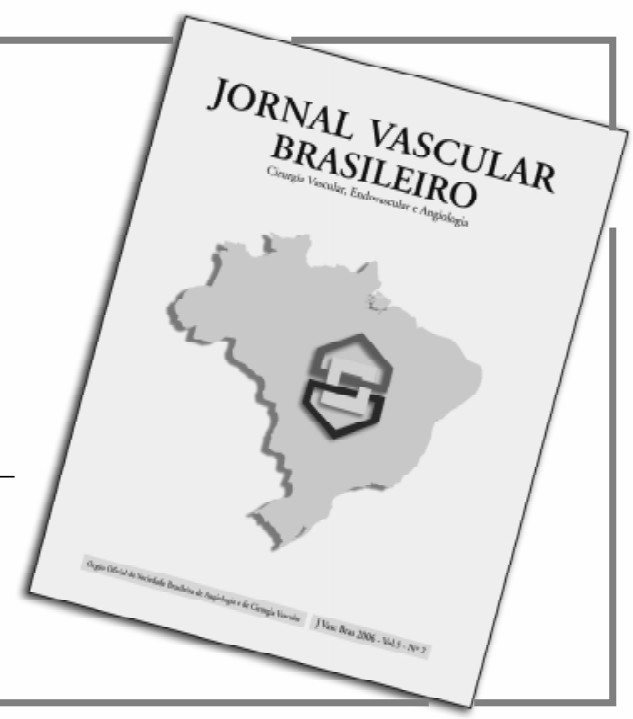

